\title{
Locus of Equity and Brand Extension
}

\author{
STIJN M. J. VAN OSSELAER \\ JOSEPH W. ALBA*
}

Prevailing wisdom assumes that brand equity increases when a brand touts its desirable attributes. We report conditions under which the use of attribute information to promote a product can shift the locus of equity from brand to attribute, thereby reducing the attractiveness of extension products. This effect is moderated by the degree of ambiguity in the learning environment, such that prevailing wisdom is refuted when ambiguity is low but is supported when ambiguity is high.

$\mathrm{C}^{\circ}$ onsumers purchase products to obtain benefits, and products deliver benefits at least in part through the attributes they possess. It is commonly assumed that emphasizing a product's favorable attributes increases its attractiveness and enhances brand equity, even when those attributes have a negligible effect on objective product performance (Brown and Carpenter 2000) or are nondiagnostic of brand superiority (Hoch and Deighton 1989). We argue that although product attractiveness is likely to be enhanced by the promotion of favorable attributes, an accompanying decrease in brand equity can occur.

Brand equity has been conceptualized in a variety of ways (e.g., Aaker 1991; Erdem and Swait 1998; Fournier 1998; Keller 1998). Consistent with common measurement approaches (e.g., Green and Wind 1975; Louviere and Johnson 1988; Park and Srinivasan 1994), it is operationally defined here in terms of the effect of brand names on product evaluations. We specifically propose that emphasizing an attribute can reduce brand equity by changing the locus of equity from the brand name to the attribute. This change in the locus of equity should not lower the product's attractiveness in its original product category but should affect evaluations of extension products that do not include the attribute emphasized in the original category-even when the benefit provided by the attribute is valued in both the original and extension categories.

\section{THEORETICAL BACKGROUND}

It is commonly believed that the benefits associated with particular attributes transfer to brands whose products con-

*Stijn M. J. van Osselaer is associate professor of marketing and Kilts Center for Marketing Faculty Fellow, Graduate School of Business, University of Chicago, Chicago, IL 60637 (e-mail: stijn.vanosselaer@gsb. uchicago.edu), Joseph W. Alba is distinguished professor of marketing, Warrington College of Business, University of Florida, Gainesville, FL 32611 (e-mail: albaj@dale.cba.ufl.edu). This research was supported by the James M. Kilts Center for Marketing and the True North Communications Inc. Faculty Research Fund at the University of Chicago Graduate School of Business. The authors thank Marcus da Cunha and Els De Wilde for their assistance. tain those attributes, much like the transfer of affect from advertisements to brands. For example, the security benefit conveyed by armed guards and armored cars transfers to Brinks, the strength and power of heavy machinery transfers to Caterpillar, and the cavity-preventing benefit provided by fluoride transfers to Crest.

It is also commonly believed that these associations facilitate entry into other product classes in which these benefits are valued-even when the original benefit-inducing attributes do not exist in the extension category. For example, there is no tangible attribute of Brinks courier service in a Brinks home security system, no tangible attribute of Caterpillar construction equipment in Caterpillar work clothes, and no tangible attribute of Crest toothpaste in a Crest toothbrush. Nonetheless, Brinks home-security systems should be judged to be protective, Caterpillar clothing should be seen as strong and durable, and a Crest toothbrush should be viewed as an effective cavity-fighter. In reality, common wisdom is rarely tested. The necessary control to test for such brand enhancement is the situation in which a brand is touted in its original category as providing a particular benefit but without making reference to a specific supportive attribute.'

Although empirical confirmation is lacking, the underlying rationale for brand enhancement is consistent with spreading-activation theories of human associative memory (e.g., Anderson and Bower 1973; Anderson and Lebiere 1998). The basic argument is that consumers associate concepts whenever the concepts are experienced together. Thus, it behooves firms to associate their brands not only with good consumption outcomes but also with product attributes that are themselves associated with those consumption outcomes.

\footnotetext{
'Broniarczyk and Alba (1994) suggest that the attractiveness of a brand extension varies as a function of the relevance of specific attributes or benefits in the extension category. Note that their findings are orthogonal to the present research, which manipulates the presence of attribute information in the original category while holding constant the benefit overlap between the original and extension categories at a high level.
} 
By contrast to the brand-enhancing prediction made by spreading-activation models, cue-interactive models of learning suggest that brand equity and brand extensions might be harmed by the use of attribute information to promote the original product. Cue-interaction models have two basic properties. First, they assume that the predicted level of a consumption outcome or benefit (e.g., quality) is a sum of the strengths of its associations with all currently present cues, including brand names as well as attributes (an assumption that is consistent with conjoint analysis and multiattribute attitude measurement). Second, they assume that strengthening and weakening of association strengths is directed toward eliminating any discrepancy between the predicted and actual levels of a consumption outcome. Thus, when consumers have both predictive brand information and predictive attribute information, the strengths of their associations-and therefore their influence on benefit predictions - are largely a zero-sum game. Insofar as "brand equity" can be operationally defined as the influence of brand names on benefit predictions (e.g., Keller 1993, 1998), "attribute equity" can analogously be defined as the influence of attribute information on benefit predictions. If brand and attribute equity are defined in this way and if cue-interactive models are valid, equity will be divided among cues (or among their representations in memory), and brands and attributes will often compete for equity. The use of benefitinducing attributes in the original category, therefore, could decrease the value consumers place on a product's name by switching the locus of equity to its attributes.

A decrease in brand equity because of a change in the locus of equity does not necessarily lead to less extreme benefit predictions and product evaluations, especially in the category of origin. In the original category, equity lost by a brand is balanced by a gain in the equity of one or more attributes. Thus, predicted benefit levels for the original product as a whole are undiminished. The only significant problem in the original category should occur when the attribute that gained equity from the brand is shared by other brands, in which case the predicted benefit levels of brands sharing the same attribute converge, and competitive pressure increases. On the other hand, a shift in the locus of equity from brand to attribute may have a pronounced effect on the evaluations of extension products. A reduction in brand equity cannot be balanced by an increase in attribute equity if the extension product does not have that attribute. Thus, although the underlying decrease in brand equity resulting from weakened brand-to-benefit associations is the same in the original and extension categories, the practical implications for the original and extension product will often differ.

Competition for equity between brand and attribute is inconsistent with spreading-activation theories, which hold that the learning of an association from one cue to an outcome should be unaffected by associations from other cues to that same outcome (van Osselaer and Janiszewski 2001). The predictions made by cue-interactive models are not widely espoused in consumer research but are prominent in influential theories of animal learning (Pearce and Bouton 2001), are prominent in some models of human causal judgment (Shanks, Medin, and Holyoak 1996), and have even been invoked in the study of brand equity (van Osselaer and Alba 2000). However, no research has properly investigated the direct trade-off between brand equity and attribute equity (i.e., the zero-sum assumption). To do so requires a design in which the learning of brand-benefit information is contrasted with the simultaneous learning of brand-attributebenefit information. Moreover, there is no research in any context that investigates this critical trade-off across judgment categories, such as when brands extend into new product classes.

These issues are examined in the following experiments: We find support for cue-interactive models, but we also can accommodate anecdotal evidence regarding the advantages to be gained from the promotion of benefit-inducing attributes. In the end, we argue that the validity of different models is contextually determined, and we offer supporting evidence for one important moderating factor.

\section{EXPERIMENT 1}

The first experiment tested the hypothesis that the use of attribute information leads to a reduction in the influence of brand name on quality judgments - both in the category of origin (line extensions) and in an extension category-by manipulating the information to which consumers were exposed while they learned about product quality in the original category. In the attribute conditions, participants were shown product profiles that included both brand and attribute cues that were predictive of product quality. In the no-attribute conditions, only brand information was predictive of product quality. If benefit-inducing attributes harm brand equity, later quality judgments of additional products in the original and extension categories should be less influenced by brand name in the attribute conditions than in the noattribute conditions. A second manipulation designed to assess generalizability varied whether specific attribute and quality levels were unique to a single brand or shared by a pair of brands.

\section{Method}

Design and Participants. A 2 (attribute vs. no attribute) $\times 2$ (unique vs. multiple brands per quality level) completely randomized factorial design was used. A total of 112 undergraduates participated in return for extra course credit, with cell sizes ranging from 27 to 30 . Four groups of participants were shown a number of product descriptions that included information about product features as well as overall quality level. In the no-attribute conditions, only one feature-brand name-was predictive of quality. In the attribute conditions, two features - brand name and a product attribute-were predictive of quality. In the unique-brands conditions, one brand name was associated with high quality, and one brand name was associated with low quality. In the multiple-brands conditions, two brand names were 
associated with high quality, and two brand names were associated with low quality. The predictive attribute in the attribute conditions always had one level associated with high quality and one level associated with low quality. In the test phase, participants were asked to indicate the quality level of additional profiles in the original category as well as from an extension category. (Tables A1-A3 contain summaries of the experimental and stimulus designs for each experiment.)

Stimuli. The learning phase in the unique-brands conditions consisted of 12 profiles of down jackets. In the attribute-unique-brands condition, each profile described a particular down jacket, listing its model number, brand name (Hypalon or Riken), fill type (Alpine-class down fill or regular down fill; cf. Carpenter, Glazer, and Nakamoto 1994), cover material (cotton or synthetic), stitching (always extra tight), and quality level (high or low). Six of the down jackets were high quality, and six were low quality. Two features, brand and fill type, were perfectly predictive of quality. All high-quality jackets carried the Hypalon name and had an Alpine-class down fill. All low-quality jackets carried the Riken name and had a regular down fill. Stitching and cover material were nonpredictive filler features. All jackets had extra-tight stitching. Half of the high-quality jackets and half of the low-quality jackets used cotton cover material. The other half used synthetic cover material. Thus, stitching was a constant filler feature, and cover material was a varying filler feature that was uncorrelated with quality. These attribute combinations yielded two attribute profiles for each brand, each of which was presented three times with its own model number. The profiles in the no-attribute-unique-brands condition lacked information about the fill type but otherwise were identical to those in the attribute-unique-brands condition.

In the multiple-brands conditions, there were two brands per quality level, and participants were exposed to 24 instead of 12 profiles. The number of stimulus profiles was doubled to keep the number of exposures to each brand name identical across conditions. In the attribute-multiple-brands condition, participants were exposed to the same 12 profiles used in the attribute-unique-brands condition, along with six high-quality jackets that carried the Leafield brand name and six low-quality jackets that carried the Bering brand name. Aside from model numbers, the Leafield profiles matched those of Hypalon, and the Bering profiles matched those of Riken. The no-attribute-multiple-brands condition differed from the attribute-multiple-brands condition only by the absence of information about the fill-type attribute.

Procedure. Participants were run in groups of one to 12 and were randomly assigned to conditions. Each participant was seated in front of a personal computer shielded from other participants. Instructions and stimuli were presented via computer. Instructions informed participants about the type of stimulus information they would receive and requested that they try to "learn how to predict the quality level of down jackets." The stimulus profiles were then presented one-by-one on a self-paced basis. Immediately thereafter, two dependent measures were collected.

Measures. The first measure consisted of 16 additional profiles of down jackets that contained information about all four jacket features presented earlier. The 16 profiles were constructed as a $4 \times 2 \times 2$ factorial combination of the four brand names, two fill types, and two types of the uncorrelated filler feature (cover material). The constant filler feature (extra-tight stitching) was also added to each profile. For each of the 16 jackets, participants indicated the quality level on a seven-point scale ranging from -3 (low quality) to +3 (high quality). The second measure consisted of 16 profiles of products in the extension category of woolen sweaters. These 16 profiles were constructed as a $4 \times$ $2 \times 2$ factorial combination of the four brand names and of two types each of two additional varying attributes (wool type: $100 \%$ wool or $100 \%$ lamb's wool; origin of the wool: Ireland or Poland). All profiles included one constant feature (machine washable). A seven-point quality scale ranging from -3 (low quality) to +3 (high quality) again was used.

\section{Results}

Because hypotheses in this study are at the level of the feature dimension (e.g., influence of brand information instead of just the "Hypalon brand"), the conceptual dependent variable is the difference in evaluation between products that have different levels of a feature. For example, to assess the value placed on brand information in quality judgments of down jackets in the attribute-unique-brands condition, a mean feature effect (MFE) of brand was computed by subtracting the average quality rating for products identified by the Riken brand name from the average quality rating for products identified by the Hypalon brand name. Thus, the brand MFE of 2.50 for down jackets in the attribute-uniquebrands condition in table 1 was computed by subtracting the average quality rating for Riken jackets $(-1.07)$ from the average quality rating given to Hypalon jackets (1.43). This MFE can be interpreted as a brand part-worth utility

TABLE 1

MEAN FEATURE EFFECTS (EXPERIMENT 1)

\begin{tabular}{lccc}
\hline \hline & $\begin{array}{c}\text { No-attribute } \\
\text { condition }\end{array}$ & $\begin{array}{c}\text { Attribute } \\
\text { condition }\end{array}$ & Difference \\
Category & & & \\
\hline Brand effects: & & & \\
Category of origin: & 4.95 & 2.50 & -2.45 \\
$\quad$ Unique brands & 3.64 & .79 & -2.85 \\
$\quad \begin{array}{l}\text { Multiple brands } \\
\text { Extension category: }\end{array}$ & & & -1.74 \\
$\quad$ Unique brands & 4.00 & 2.26 & -2.77 \\
$\quad$ Multiple brands & 3.41 & .64 & \\
Attribute effects: & & & 2.86 \\
Category of origin: & & 2.85 & 3.54 \\
$\quad \begin{array}{l}\text { Unique brands } \\
\text { Multiple brands }\end{array}$ & -.01 & 4.14 & \\
\hline
\end{tabular}


or a brand weight, which is a common measure of brand equity.

To summarize, the results suggest that the use of attribute information to reinforce product quality harms brand equity. Specifically, the use of predictive fill-type information reduced the impact of brand information on quality predictions in both the category of origin and the extension category, regardless of whether brands were unique in quality and attribute (see table 1).

Original Category. The down jacket responses were first subjected to an omnibus ANOVA that included the experimental manipulations (attribute vs. no attribute and unique vs. multiple brands) and the brand, fill type, and cover material in the original-category test profiles as independent variables. Rated quality was the dependent variable. Because participants in the unique-brands conditions had not been exposed to the Leafield and Bering brand names during the learning phase, we excluded the eight profiles with those brand names from the omnibus analysis. One participant in the no-attribute-multiple brands condition was excluded from the analysis because of an incomplete set of responses. Results showed a significant interaction of brand and the attribute-no-attribute manipulation, indicating that the impact of brand information on quality judgments was reduced when a predictive attribute was provided during learning $(F(1,107)=40.91, p<.001)$. This effect occurred regardless of the number of brands per quality level during learning (unique vs. multiple brands; $F(1$, $107)=.23$ ) and was not qualified by any other higher-order interactions (all $p$ 's $>.10$ ). Follow-up analyses showed a significant negative effect of the use of fill type on the influence of brand name on quality predictions in both the unique brands $(F(1,52)=18.44, p<.001)$ and multiple brands $(F(1,55)=22.67, p<.001)$ conditions. The latter effect was also significant when the eight profiles using the Leafield and Bering brands were included $(F(1,55)=$ $28.80, p<.001)$.

One obvious implication of the cue-interaction hypothesis is that fill type should have a strong effect on original-category evaluations in the attribute conditions. The difference of 3.20 in the size of the attribute effect between the attribute conditions (MFE = 3.51) and the no-attribute conditions $(\mathrm{MFE}=.31)$ is statistically significant $(F(1,107)=$ $83.57, p<.0001)$ and comparable in magnitude with the corresponding negative difference for brand information. This effect was observed irrespective of the number of brands per quality level during learning $(F(1,107)=.94)$ and was statistically significant for both the unique brands $(F(1,51)=$ $37.66, p<.0001)$ and multiple brands $(F(1,55)=50.00$, $p<.0001)$ conditions. These results suggest that brand equity in the no-attribute conditions shifted to the predictive attribute (fill type) in the attribute conditions. The same result is evident in the corresponding conditions of the remaining experiments.

Extension Category. The same procedure was used to analyze the extension category. An omnibus ANOVA was first run that included the experimental manipulations (at- tribute vs. no attribute and unique vs. multiple brands) and the brand, type of wool, and the wool's country of origin in the extension category test profiles as independent variables. Rated quality was the dependent variable. One participant in the attribute-unique-brands condition was excluded from the analysis because of an incomplete set of responses. As in the original category, a significant interaction of brand and the attribute versus no-attribute manipulation was found $(F(1,107)=30.09, p<.001)$, indicating that the influence of brand information on quality judgments was significantly dampened when predictive attribute information was provided during learning in the original category. (This interaction also refutes a scale-effect explanation for the main result in the original category. The original predictive attribute was absent from the extension category, and, therefore, the reduced brand effect cannot be attributed to the need by participants in the attribute condition to fit the influences of two important cues into a constant scale.) The interaction of brand and the attribute versus no-attribute manipulation was not qualified by any higher-order interactions (all $p$ 's $>.10$ ). Follow-up analyses showed a significant negative effect of the use of fill type in the category of origin on the effect of brands on predicted quality for woolen sweaters in both the unique-brands $(F(1,51)=9.43, p<.01)$ and multiple-brands $(F(1$, $56)=21.96, p<.001)$ conditions. The latter effect also was significant when the eight profiles using the Leafield and Bering brands were included $(F(1,56)=20.02, p<.001)$.

It might be argued that the effect in the extension category was strengthened or caused by first having provided evaluations in the original category. To test this alternative, we ran a reduced experiment that included the two uniquebrands conditions but also counterbalanced the order of the dependent measures. The effects found in experiment $1 \mathrm{com}-$ pletely replicated (all $p$ 's $<.001$ ), and no effect was affected by measurement order (all $p$ 's $>.10$ ).

\section{Discussion}

The results support the hypothesis that the presence of predictive attribute information can lead to a reduction in the influence of brand names on quality judgments, both in the original category and in an extension category, by shifting the locus of equity from the brand to the attribute. Such shifts in equity generally are beneficial to consumer welfare. Whereas brands may have some direct causal influence on product utility (e.g., because they signal prestige to self and others), brands also often function as labels that predict quality but do not cause it. Consumer welfare is increased when consumers learn the true causal determinants of quality.

Unfortunately, even when consumers learn to value attributes, welfare is not assured. Consider the case in which firms position their offerings in terms of seemingly attractive but pseudodiagnostic attributes. For example, Folgers coffee positions itself as being "mountain grown"- -an attribute that in reality is shared by most coffees. In such cases, an equity shift from brand to attribute may not increase consumer 
welfare. Prior research suggests that consumers' ability to learn the true causal determinants of product quality is influenced by the order in which information is learned. When predictive but noncausal information is learned first, subsequent learning of the underlying causal information can be inhibited (van Osselaer and Alba 2000). Such instances arise in consumer contexts when consumers become aware of either the brand or the brand and its positioning attribute prior to more detailed and diagnostic information. Based on cue-interaction theory and the results of experiment 1 , we make the following predictions regarding the weight consumers will place on the brand itself: (1) When all information is learned simultaneously, equity will be surrendered by the brand to the predictive attributes. (2) When the brand is paired with a positioning attribute prior to information about other predictive cues, the brand will surrender equity to the positioning attribute, but subsequently presented predictive cues (including truly causal attributes) will gain little equity. (3) When the predictive value of the brand is learned prior to the presentation of any other predictive cue, the brand will retain its equity. These outcomes are expected to occur both in the category of origin and in an extension category.

\section{EXPERIMENT 2}

To investigate our hypotheses, participants in half of the conditions received all information about each item simultaneously; in the other conditions, participants were preexposed to brand or brand-plus-positioning-attribute information before encountering information about the other predictive attribute. For present purposes, a positioning attribute is operationally defined as one that is paired at all times with a particular brand name. In the external world, such attributes may indicate real differences among brands or may portray false distinctions (e.g., mountain-grown coffee). In the experiment, fill type was arbitrarily chosen to play this role.

\section{Method}

Design and Participants. A 2 (positioning attribute vs. no positioning attribute) $\times 2$ (preexposure vs. no preexposure) completely randomized factorial design was used. A total of 160 people participated in groups of less than 10 .

Stimuli and Procedure. The procedure and format of the stimuli were similar to those used in experiment 1 . As in the attribute condition of experiment 1 , participants in the positioning-attribute-no-preexposure condition were exposed to 12 profiles of down jackets that contained brand name and fill type, which were predictive of quality, along with two filler features (cover material and stitching) that were not predictive of quality. Unlike experiment 1 , another predictive attribute was included - fill rating - that was perfectly correlated with both the brand and fill type. All six high-quality jackets were Hypalon brand jackets that had Alpine-class down fill and a fill rating of 550. All six low- quality jackets were Riken brand jackets that had regular down fill and a fill rating of 500 . The 12 profiles in the nopositioning-attribute-no-preexposure condition were identical to those in the positioning-attribute-no-preexposure condition, except that they did not mention fill type. In the positioning-attribute-preexposure condition, participants received the same 12 profiles as in the corresponding nopreexposure condition but were preexposed to four other profiles. In addition to quality, these preexposed profiles listed brand, fill type, two filler features, but not the other predictive attribute (fill rating). Brand and fill type were again predictive of quality, and the two filler features were not predictive of quality. In the no-positioning-attribute-preexposure condition, no reference was made to fill type in any of the profiles. (A design summary is reported in table A2.) Thus, the main differences between experiments 1 and 2 are that experiment 2 included another predictive attribute in all its conditions and that half the participants were preexposed to brand or brand-pluspositioning-attribute information. After exposure to these learning profiles, participants in all conditions responded to the dependent measures in the order described below.

Measures. Three dependent measures were used. Two measures each consisted of 16 down jacket profiles constructed as a $2 \times 2 \times 2 \times 2$ factorial combination of the two brand names, fill types (the positioning attribute), fill ratings (the other predictive attribute), and cover materials (the varying but uncorrelated feature). For the first measure, participants indicated whether each profiled product was high or low in quality. The second measure was identical but employed the seven-point scales from experiment 1 . (The order of the two types of profile measures was manipulated in a pretest, and no order effects were found.)

A third measure consisted of two profiles in the extension category of woolen sweaters. Both profiles mentioned that the wool used in the product originated in Ireland, that the product was machine washable, and that the type of wool used was lamb's wool. The two profiles in this extension category differed only in terms of the sweater's brand name, that is, Hypalon versus Riken. Thus, the third measure allowed measurement of brand equity in an extension category. Participants assessed quality of the two sweaters on a seven-point scale. Four participants failed to complete this measure.

\section{Results}

To summarize, results showed that the use of a positioning attribute does significant damage to brand equity, especially when brand information is received before information about the other predictive attribute. Table 2 presents the mean feature effects for the seven-point scale measures.

Original Category. An omnibus ANOVA performed on the seven-point quality judgments showed that when presented in the context of another predictive attribute, a positioning attribute reduces the effect of brand on quality 
TABLE 2

MEAN FEATURE EFFECTS (EXPERIMENT 2)

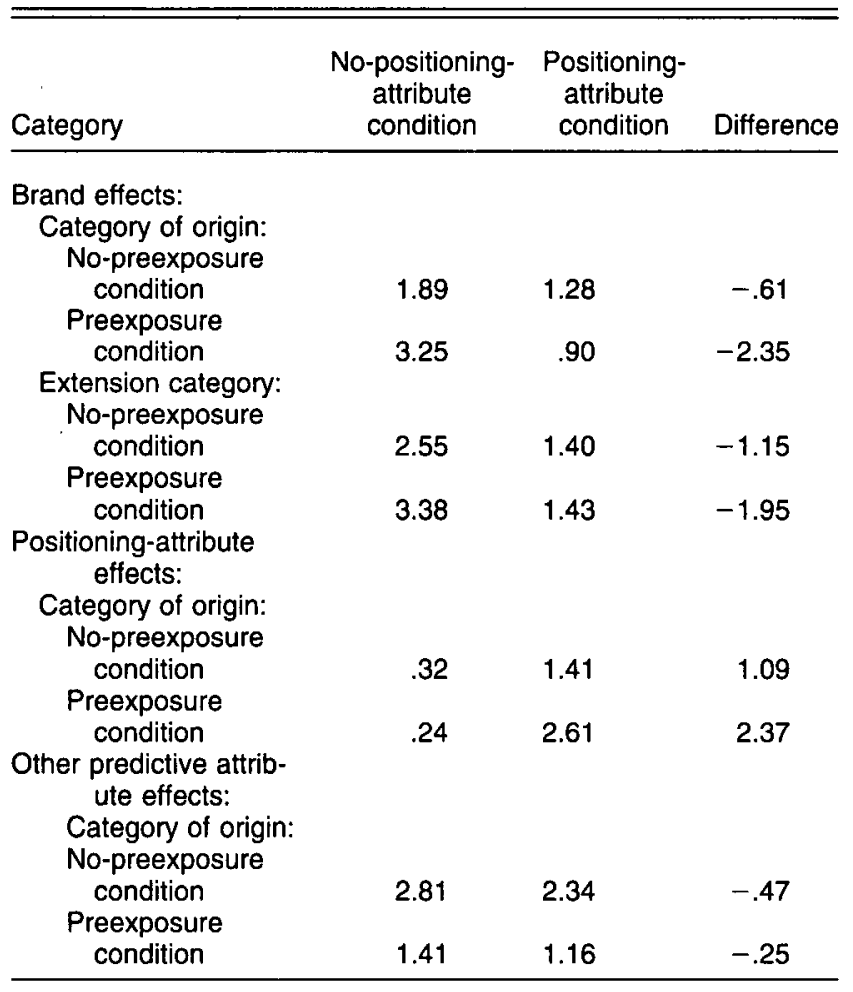

judgments more when brand and positioning attribute are preexposed than when all predictive cues are encountered simultaneously $(F(1,155)=8.41, p<.01)$. A logistic regression on the binary quality judgments that contained the brand names plus the preexposure- and positioning-attribute factors as independent variables showed the same effect (asymptotic $t=4.72, \quad p<.001$ ). Follow-up analyses showed a significant reduction in the brands' influence on quality judgments when a positioning attribute was present during learning in the preexposure conditions $(F(1,77)=$ $37.69, p=.001$, and asymptotic $t=-7.55, p<.001$ ) but not in the no-preexposure conditions $(F(1,78)=1.70$, $p=.20$, and asymptotic $t=-1.39, p=.17$ ).

In descriptive terms, brand equity was greatest when participants learned that brand name was a reliable predictor of quality prior to learning any attribute information. However, when the brand was paired with a positioning attribute, equity shifted from the brand to the positioning attribute. The other predictive attribute, which in the current design was meant to simulate the true determinant of quality, was given a high weight only when it was viewed concurrently with all other information.

Extension Category. More pertinent to our primary objective, a similar pattern was observed in the extension category, although the interaction failed to attain statistical significance $(F(1,153)<1)$. Instead, a strong negative effect of the positioning attribute was observed regardless of preexposure $(F(1,153)=13.95, p<.001)$. This effect was significant within the preexposure conditions $(F(1,77)=$ $11.80, p<.01)$ and marginally significant within the nopreexposure conditions $(F(1,76)=3.60, p=.06)$. That is, the value of the brand in the extension category was greatly diminished when the brand had been paired with a positioning attribute in its original category.

\section{Discussion}

As in experiment 1 , a shift in equity from brand to attribute and a general diminution of brand equity in both the original and extension categories was observed. The wisdom of using a positioning attribute to protect equity received mixed support. When the brand was paired with a positioning attribute prior to exposure to detailed information - as would be the case in many consumer contexts - the positioning attribute claimed more equity. Firms may be satisfied with such a result if they can co-opt the positioning attribute. However, the use of the positioning attribute produced an undesirable outcome for the firm in an extension category. The shift in equity harmed the firm's ability to extend to an analogous category because it simultaneously inhibited consumer reliance on the brand cue. It is important to note that the predictive attributes used in both experiments were plausibly linked to the primary benefit sought in the original category-a benefit that was also relevant in the extension category. Thus, it cannot be argued that the results were driven by the perceived fit between the original and extensions categories (cf. Broniarczyk and Alba 1994).

The results thus far are clearly more consistent with infrequently invoked cue-interaction models than with the spreading-activation views popular in consumer research. However, cue-interaction models assume that learning depends on (conscious or nonconscious) prediction of benefit levels and subsequent feedback about those benefit levels. We predict that such a predictive learning process is less likely to occur when feedback is very ambiguous or even nonexistent. The next experiment tests this hypothesis.

\section{EXPERIMENT 3}

A variable of interest to consumer researchers but notably absent from the learning literature on cue interaction is the presence versus absence of clear, unambiguous outcome (e.g., quality) information (e.g., Hoch and Ha 1986; Wood 2001). In learning tasks, ambiguity can be operationalized in terms of a lack of discriminating outcome information, as in the consumption of credence goods. When no clear outcome information is present, naive consumers may find it difficult to isolate the attributes that predict quality. Unlike simple association in the spreading-activation tradition, predictive learning consists of an updating process that is facilitated by unambiguous feedback about the accuracy of one's predicted outcomes. When ambiguity is high and consumers are uncertain, consumers may favor a brand that has an aura of quality resulting from the transfer of associations from an attractive attribute. In such cases, brand and attribute equity may not be negatively related, inasmuch as the brand 
gains rather than loses equity though its association with the attribute. We examined this possibility by manipulating the presence of both a covarying attribute and unambiguous quality information during learning.

\section{Method}

Design and Participants. A 2 (attribute vs. no attribute) $\times 2$ (quality information vs. no quality information) completely randomized factorial design was used. A total of 122 people participated in groups of 12 persons or less. Sixty of the 122 participants took part in this experiment after participating in an unrelated experiment earlier in the same experimental session.

Stimuli, Procedure, and Measures. Stimuli, procedure, and measures were similar to the unique-brands conditions in experiment 1 , with two exceptions. In the noquality-information conditions, product profiles in the learning phase did not contain a statement mentioning the product's quality level (high or low). In both the original and extension category, eight test profiles were used. Each profile included one of two brand names instead of one of four brand names in experiment 1.

\section{Results and Discussion}

Original Category. Table 3 contains the means in each condition. The data first were subjected to an omnibus ANOVA that included the order of the experiment in the experimental session (before vs. after the unrelated experiment). The order factor did not moderate the effects of interest and was not considered further (all $p$ 's $>.10$ ). Next, an ANOVA was run with only the main experimental manipulations (attribute vs. no attribute; quality vs. no quality information) and the levels of brand, fill type, and cover material in the test profiles as independent variables. Rated quality was the dependent variable. As expected, a significant three-way interaction of brand and the quality versus no-quality and attribute versus no-attribute manipulations was found $(F(1,118)=10.93, p<.01) .^{2}$ Follow-up analyses showed that when participants received unambiguous outcome information during learning (in the quality conditions), the pairing of a brand name with a covarying attribute during learning reduced the impact of that brand on quality judgments $(F(1,58)=7.92, p<.01)$. When no covarying attribute was used during learning, the difference in

\footnotetext{
${ }^{2}$ The three-way interaction of brand and the quality-no-quality and attribute-no-attribute manipulations was qualified by a four-way interaction with the type of down fill used in the measurement profiles. Follow-up analyses suggested that this was not due to a differential effect of brand name as a function of whether it was combined with the type of down fill used in the learning phase (i.e., it was not the case that the brand effect was different for products that participants had vs. had not seen previously). Instead, the follow-up analyses showed that in the no-quality conditions the effect of brand name was reduced for products that had Alpine-class down fill. This was likely because of a ceiling effect, as all Alpine-class profiles were evaluated very positively. Thus, this higher-order interaction does not alter the basic interpretation of the results.
}

TABLE 3

MEAN FEATURE EFFECTS (EXPERIMENT 3)

\begin{tabular}{lccc}
\hline \hline Category & $\begin{array}{c}\text { No-attribute } \\
\text { condition }\end{array}$ & $\begin{array}{c}\text { Attribute } \\
\text { condition }\end{array}$ & Difference \\
\hline $\begin{array}{c}\text { Brand effects: } \\
\text { Category of origin: } \\
\text { Quality-information } \\
\quad \text { condition }\end{array}$ & 4.10 & 2.53 & -1.57 \\
$\begin{array}{c}\text { No-quality-informa- } \\
\text { tion condition }\end{array}$ & -.19 & .14 & .33 \\
$\begin{array}{c}\text { Extension category: } \\
\text { Quality-information } \\
\text { condition }\end{array}$ & 3.18 & 2.00 & -1.18 \\
$\quad \begin{array}{c}\text { No-quality-informa- } \\
\text { tion condition }\end{array}$ & -.11 & .13 & .24 \\
$\begin{array}{c}\text { Attribute effects: } \\
\text { Category of origin: } \\
\text { Quality-information } \\
\text { condition }\end{array}$ & .38 & 2.41 & 2.03 \\
$\begin{array}{c}\text { No-quality-informa- } \\
\text { tion condition }\end{array}$ & 1.10 & 1.12 & .02 \\
\hline
\end{tabular}

quality judgments between products carrying the Hypalon brand name and products carrying the Riken brand name was much larger (MFE $=4.10)$ than the difference between those brand names when a covarying attribute had been used $(\mathrm{MFE}=2.53)$.

By contrast, when participants did not receive unambiguous outcome information during learning (i.e., the no-quality conditions), a positive covarying attribute during learning increased the positive impact of the brand name $(F(1$, $60)=4.02, p<.05)$. The difference in quality judgments between products carrying the Hypalon brand name and products carrying the Riken brand name was more positive when Hypalon was accompanied by Alpine class and Riken was accompanied by regular down fill during learning (MFE $=.14$ ) than if no fill-type information was used (MFE $=-.19$ ). Thus, the effect of using a positive covarying attribute was directionally opposite to the effect observed in the unambiguous-outcome conditions.

Extension Category. The same procedure was used to analyze the extension category (woolen sweaters) responses. The order of the present and the unrelated experiment in the experimental session did not moderate the effects of interest and was not considered further (all $F$ 's $<1$ ). As expected, the critical three-way brand by attribute versus no-attribute by quality versus no-quality interaction was significant $(F(1$, $118)=6.47, p<.02$ ), indicating that the presence of a covarying attribute affected the brand effect on extension product evaluations differently as a function of outcome ambiguity. This effect was not qualified by higher-order interactions (all $p$ 's $>.19$ ). Follow-up contrasts again showed that when unambiguous outcome information was provided, the use of an attribute in the original category led to a significant attenuation of the difference between the Hypalon and Riken brands $(F(1,58)=4.62, p<.05$; from MFE $=3.18$ in the noattribute condition to MFE $=2.00$ in the attribute condition). 
By contrast, when no unambiguous outcome information was provided, the use of the attribute in the original category led to an increase in the perceived quality of Hypalon versus Riken woolen sweaters $(F(1,60)=2.83, p<.10$; from MFE $=-.11$ in the no-attribute condition to MFE $=.13$ in the attribute condition). As in the category of origin, the additional attribute harmed a (superior) brand when outcome information was unambiguous but helped when quality was ambiguous.

\section{GENERAL DISCUSSION}

The present results illustrate a counterintuitive effect of promoting a brand with quality-related attributes but also demonstrate that this effect is moderated by the ease with which consumers are able to learn about quality. When learning was relatively easy because of the provision of unambiguous outcome information, the presence of an attribute that covaried with the outcome shifted equity from the brand to the attribute. When learning was difficult because of high ambiguity, seemingly attractive attributes bolstered the brand instead.

\section{Some Additional Observations}

Robustness. Given the many possible stimulus configurations, the present research is naturally incomplete. For example, we did not investigate situations in which quality varied within brand, although our assumption of low variance is far from heroic. In addition, deviations from perfect brand-quality and brand-attribute correlations were not extensive, although the multiple-brands conditions of experiment 1 demonstrate that perfect correlations are not required to obtain a shift in equity from brand to attribute. We therefore conducted a simulation study involving a number of different stimulus configurations. The simulation was based on the most widely supported cue-interaction model, that is, the least mean squares adaptive-network model (Gluck and Bower 1988). We started with a schematic representation of the stimuli used in the unique-brands conditions of experiment 1, which had perfect correlations between brand information and attribute information, between brand information and quality information, and between attribute information and quality information. We also constructed three stimulus sets that maintained the perfect brand-attribute correlation but reduced the brand-quality and attributequality correlations to $.67, .33$, and .00 ; three stimulus sets that maintained the perfect attribute-quality correlation but reduced the brand-quality and brand-attribute correlations to $.67, .33$, and .00 ; and three stimulus sets that maintained the perfect brand-quality correlation but reduced the attribute-quality and brand-attribute correlations to $.67, .33$, and .00 . To guard against confounding these manipulations with other factors and to retain the mapping to our experiments, filler attribute-quality, brand-filler attribute, and predictive attribute-filler attribute correlations were kept at zero, and the base rate of high-quality products was kept at .50. Also, as in experiment 1 , the stimulus sets consisted of 12 stimuli, and all features (brand names, attributes) were presented equally often. One hundred learning simulations of each stimulus set were run using randomly chosen stimulus orders.

Results indicate that the brand-equity diminishing effect of predictive attribute information is robust to imperfect correlations. When brand-quality and attribute-quality correlations are both reduced, the effect obtains in $100 \%$ of the orders at correlation levels of .67 and .33 . When only the brand-quality correlation is reduced to $.67,100 \%$ of the orders yield the effect; at .33 , the effect obtains in 88 of 100 simulated orders. When the brand-quality correlation is perfect but the attribute-quality correlation is reduced, the effect is perfectly robust at an attribute-quality correlation of .67 but disappears in about half the cases when the attribute-quality correlation is lowered to .33 . Taken together, these results suggest that there is little reason to expect a lack of robustness because of stimulus configuration.

In addition to being robust to imperfect correlations, cueinteraction models predict that competition between cues is robust to the nature of the cues. For example, the same type of effect should be found when two attributes are presented simultaneously as when a brand and an attribute are presented simultaneously.

Partitioning the Brand Effect. The MFEs by themselves do not describe the extent to which decreases in the impact of brand information on quality evaluations reflect changes in the equity of the high-quality brand (e.g., Hypalon) versus changes in the equity of the low-quality brand (e.g., Riken). One way to detect the share of the cue-interaction effect determined by the positive versus negative brand is to compare their evaluations to that of a new brand. The unique-brands conditions of experiment 1 allow such an analysis because the Leafield and Bering brands were new to participants at the time of test. The analysis shows that $48 \%$ of the effect of using attribute information in the original category and $38 \%$ of the effect in the extension category resulted from the less-positive evaluation of the Hypalon brand. Although the absence of new brands in the test phases of the other experiments precludes similar analysis, these data suggest that the effect is not restricted to brands of a particular valence.

Cue Interaction versus Discounting. One might argue that our basic result reflects nothing more than a simple discounting effect common to causal reasoning (e.g., Kelley 1973). Even if true, such an explanation would not nullify the conclusions of this research as they pertain to the prevailing wisdom on branding and spreading-activation-based models. More to the point, the present results are not friendly to a discounting account. Specifically, the different patterns of results observed in experiment 2 cannot be explained by simple discounting but are congenial to cue-interaction models. Experiment 3 provides results that are both consistent and inconsistent with discounting depending on the level of ambiguity in the outcome. When considered in the context of related research, discounting and more complex causal 
reasoning theories (e.g., Cheng 1997) lack parsimony (e.g., van Osselaer and Alba 2000). In addition, other authors have pointed out shortcomings of causal reasoning in general as an explanation of cue-interaction phenomena (e.g., Baker, Vallée-Tourangeau, and Murphy 2000; Lober and Shanks 2000).

\section{Implications}

Brand Equity and Brand Extension. This research shows that specific product associations are not merely less helpful to the brand in extension categories in which those associations are not relevant or cannot be used (Broniarczyk and Alba 1994; Desai and Keller 2002) but can actually have a deleterious effect. The results also suggest that success depends not only on specific brand-benefit associations but also on specific attribute-benefit associations and, moreover, that consumers' evaluations of extension products depend on the locus of equity. Making attribute information salient to consumers may switch the locus of equity from brands to attributes. Any equity that the attribute draws from the brand reduces brand equity and, therefore, the likely success of extension products when the attribute cannot be used for those extension products. Although such effects harm the firm, they should enhance consumer welfare when attributes truly drive product quality and the brand is merely a label that does not reflect unique underlying attributes.

When consumers lack reliable quality information, however, the positive associations carried by a product's attributes in the original category may generalize to the brand through a simple associative transfer process, thereby boosting brand equity. These transferred positive associations will have a positive impact on extension products, even when the attribute itself is not present in the extension category.

The present results also supplement the irrelevant-attributes literature (e.g., Brown and Carpenter 2000; Carpenter et al. 1994; Simonson, Carmon, and O'Curry 1994; Simonson, Nowlis, and Simonson 1993). Carpenter et al. 1994 have shown that an irrelevant attribute (Alpine class down fill) can boost product evaluations in the category of origin, even when consumers are told the attribute is irrelevant. By contrast, Simonson and his colleagues (Simonson et al. 1994; Simonson et al. 1993) have reported that irrelevant arguments and relatively unattractive, free, bundled products reduce product preference. Brown and Carpenter (2000) reconciled some of these positive and negative effects using a reasons-based theory. Unlike papers in the irrelevant-attributes literature, our focus is not on the direct effect of the attribute on product evaluations but, rather, on the effect of the attribute's presence on the value of the brand, especially in extension categories that lack the attribute.

Consumer Learning. The present results also speak to the consumer learning literature. Recent research, such as van Osselaer and Alba's (2000) investigation of sequential blocking effects, has examined cue-interaction effects but has neglected the frequent case of simultaneously present cues, the implications of cue interaction for brand extension, and the moderating effect of outcome ambiguity. The effect of ambiguity has particular theoretical significance because it supports and extends a two-systems model of associative learning in which one system learns to predict outcomes and the other simply associates co-occurring stimulus elements (see van Osselaer and Janiszewski 2001). The former should exhibit competition between cues, but the latter should not. During learning, the predictive system requires that consumers form an expectation about a benefit outcome based on information about brand and attribute cues and then register whether that outcome occurred as expected. (Whether this expectations-based process is necessarily a conscious process is unclear, given that cueinteraction phenomena have often been documented in animals.) The other system does not require the formation of expectations about particular benefit outcomes. It is likely that the procedure used in the first two experiments fostered predictive learning. However, any factor that discourages the prediction of an outcome or lowers the diagnosticity of feedback about the actual outcome-such as high outcome ambiguity-should reduce the consumer's likelihood of engaging the predictive system.

The no-quality conditions of experiment 3 were designed to create ambiguity. An intuitive explanation of the results in these conditions is that the Hypalon brand cue became associated with the Alpine-class down fill attribute cue, which already had a positive association with quality. Similarly, the Riken brand cue became associated with the regular down fill attribute, which possessed a less-positive preexisting association with quality. When asked to predict the quality of woolen sweaters (which, of course, lacked down fill), the activation of the Hypalon brand activated Alpineclass down fill, which in turn activated high quality; the activation of the Riken brand name activated regular down fill and a lesser-quality representation. Such a process is consistent with common views of consumer learning, but it is also the process against which cue-interaction effects must be considered.

\section{Future Research}

Cue-interaction effects are most likely to occur when consumers focus on a benefit as an outcome to be predicted and should require only that consumers (1) predict the extent to which consuming a product will provide certain benefits and (2) record feedback about the extent to which the product actually does provide those benefits. These conditions are not uncommon in daily life. For example, consumers often consider (i.e., predict) benefit outcomes such as taste, ease of use, reliability, and enjoyment when deciding to buy a product and often receive relatively unambiguous feedback about these qualities from direct experience or other sources. Indeed, some element of prediction is present whenever consumers have expectations of product performance. At this point, however, the degree to which cue-interaction effects require purposeful learning is a question for future research.

Until it becomes easier to predict which process will drive 
consumers' buying behavior, an initial look at effect sizes in experiment 3 suggests that brand equity might be more likely to be diminished than enhanced, even when the cueinteraction process is only partially active or only active in some consumers. In both the original and extension categories of experiment 3 , it is noteworthy that the size of the difference between the no-attribute and attribute conditions was much smaller in the ambiguous than the unambiguous quality conditions. Of course, part of this difference in effect size might result from the specific experimental context. For example, aside from the difficulty of making discriminations in an ambiguous environment, the meaningfulness of the distinction between Alpine-class and regular down fill was likely to be small for these respondents. In addition, this covarying attribute was embedded among several other attributes in both the original and extension categories. We believe that associative transfer effects might be more striking than they were in our experiment when the a priori associations between attributes and benefits are stronger and the learning environment is less cluttered. However, we also generally believe that positive transfer of association from one cue to another will often be weak relative to cue-interaction effects in which cues compete to become signals of benefits. Future research is needed to investigate the relative prevalence and impact of cue-interaction and associative transfer effects. This effort might be broadened to include transfer of affect as well. It is possible that brands often have value mostly because they are reliable and unique predictors of important benefits, not because of the warm feelings they evoke.

In addition to ambiguity and focus of prediction, other moderators of cue interaction seem plausible. For example, the negative impact of competition between cues may be avoided by positioning the original product via more abstract attributes or benefits that can be used in the extension category. Also, configural encoding of product information (i.e., as a Gestalt) would logically preclude cue competition because cues need to be encoded as separate entities to influence each other. The extent to which product information is encoded configurally is an open question, although a lack of configural processing has been observed in situations typically assumed to foster it (Hutchinson and Alba 1991).

Finally, recent research on consumer learning suggests that additional experience with a chosen attribute bundle strengthens preference for that attribute bundle when the initial choice is unambiguous (Muthukrishnan and Kardes 2001). This result might mean that when only brand information is predictive in the original category, experience in the extension category will increase the effect of brand information on evaluations in the extension category. Conversely, when predictive attribute information is used in the original category and brands are learned to be less important in the original category, experience in the extension category will make brands seem even less significant. This hypothesis is speculative but seems worthy of investigation.

\section{Conclusions}

These experiments highlight the usefulness of viewing consumers as organisms that seek to predict future consumption outcomes on the basis of cues such as brand names, product specifications, and ingredients. This perspective, which underlies cue-interactive learning models and cue-interaction phenomena, continues to generate new and nonintuitive effects while suggesting a more complex view of brands and brand equity. Our experiments show that (1) equity is composed not only of the equity residing in the family-brand name but also of the equity residing in subbrand names and individual attributes, (2) the success of brand extensions may depend on the exact locus of equity, and (3) clear predictions can be made about the locus of equity as a function of the learning context. The traditional view that meaning and affect are transferred to brands from product attributes through mere co-occurrence holds true in some situations, but we speculate that such effects may be modest in size relative to the informational effects generated by a learning process in which brands and attributes function as predictors of future consumption experience.

\section{APPENDIX DESIGN SUMMARIES \\ TABLE A1}

EXPERIMENT 1

\begin{tabular}{lcc}
\hline & \multicolumn{2}{c}{ Phase in experiment } \\
\cline { 2 - 3 } Condition & Learning & Test \\
\hline Unique brands: & $\mathrm{B}_{1} \mathrm{~A}_{1}+$ & $\mathrm{B}_{\text {original }}$ ? $\mathrm{B}_{\text {extension }}$ ? \\
Attribute & $\mathrm{B}_{2} \mathrm{~A}_{2}-$ & \\
No attribute & $\mathrm{B}_{1}+$ & $\mathrm{B}_{\text {original }}$ ? $\mathrm{B}_{\text {extension }}$ ? \\
Multiple brands: & $\mathrm{B}_{2}-$ & \\
Attribute & $\mathrm{B}_{1} \mathrm{~A}_{1}+$ & $\mathrm{B}_{\text {original }}$ ? $\mathrm{B}_{\text {extension }}$ ? \\
& $\mathrm{B}_{2} \mathrm{~A}_{2}-$ & \\
& $\mathrm{B}_{3} \mathrm{~A}_{1}+$ & \\
& $\mathrm{B}_{4} \mathrm{~A}_{2}-$ & \\
& $\mathrm{B}_{1}+$ & $\mathrm{B}_{\text {original }}$ ? $\mathrm{B}_{\text {extension }}$ ? \\
No attribute & $\mathrm{B}_{2}-$ & \\
& $\mathrm{B}_{3}+$ & $\mathrm{B}_{4}-$
\end{tabular}

NoTE. $-\mathbf{B}=$ brand; $\mathbf{A}=$ attribute $+\mathbf{+}=$ high quality; $-=$ low quality; original = original category; extension = extension category; and ? = a test item in which no quality information is given and participants are asked to predict quality. Subscripts $1-4$ refer to different levels of a feature. At test, effects of the focal attribute (only in the original category) and other attributes (e.g., filler attributes, the other predictive attribute in experiment 2) were also measured. 
TABLE A2

EXPERIMENT 2

\begin{tabular}{|c|c|c|c|}
\hline \multirow[b]{2}{*}{ Condition } & \multicolumn{3}{|c|}{ Phase in experiment } \\
\hline & $\begin{array}{l}\text { Learning } 1 \\
\end{array}$ & Learning 2 & Test \\
\hline \multicolumn{4}{|l|}{ Preexposure: } \\
\hline $\begin{array}{l}\text { Positioning attribute } \\
\text { No positioning attribute }\end{array}$ & $\begin{array}{c}\mathrm{B}_{1} \mathrm{PA}_{1}+ \\
\mathrm{B}_{2} \mathrm{PA}_{2}- \\
\mathrm{B}_{1}+ \\
\mathrm{B}_{2}-\end{array}$ & $\begin{array}{c}\mathrm{B}_{1} \mathrm{OPA}_{1} \mathrm{PA}_{1}+ \\
\mathrm{B}_{2} \mathrm{OPA}_{2} \mathrm{PA}_{2}- \\
\mathrm{B}_{1} \mathrm{OPA}_{1}+ \\
\mathrm{B}_{2} \mathrm{OPA}_{2}-\end{array}$ & $\begin{array}{l}\mathrm{B}_{\text {original }} ? \mathrm{~B}_{\text {extension }} \text { ? } \\
\mathrm{B}_{\text {originat }} \text { ? } \mathrm{B}_{\text {extension }} \text { ? }\end{array}$ \\
\hline $\begin{array}{l}\text { No preexposure: } \\
\text { Positioning attribute } \\
\text { No positioning attribute }\end{array}$ & & $\begin{array}{c}\mathrm{B}_{1} \mathrm{OPA}_{1} \mathrm{PA}_{1}+ \\
\mathrm{B}_{2} \mathrm{OPA}_{2} \mathrm{PA}_{2}- \\
\mathrm{B}_{1} \mathrm{OPA}_{1}+ \\
\mathrm{B}_{2} \mathrm{OPA}_{2}-\end{array}$ & $\begin{array}{l}\mathrm{B}_{\text {original }} ? \mathrm{~B}_{\text {extension }} ? \\
\mathrm{~B}_{\text {original }} ? \mathrm{~B}_{\text {extension }} \text { ? }\end{array}$ \\
\hline
\end{tabular}

NOTE. $-\mathrm{B}=$ brand; $\mathrm{A}=$ attribute $+=$ high quality; $-=$ low quality; original $=$ original category; and extension $=$ extension category; $\mathrm{PA}=$ positioning attribute; $\mathrm{OPA}=$ other predictive attribute; and $?=$ a test item in which no quality information is given and participants are asked to predict quality.

TABLE A3

EXPERIMENT 3

\begin{tabular}{lcc}
\hline & \multicolumn{2}{c}{ Phase in experiment } \\
\cline { 2 - 3 } Condition & Learning & Test \\
\hline Quality information: & & \\
Attribute & $\mathrm{B}_{1} \mathrm{~A}_{1}+$ & $\mathrm{B}_{\text {original }}$ ? $\mathrm{B}_{\text {extension }}$ ? \\
No attribute & $\mathrm{B}_{2} \mathrm{~A}_{2}-$ & $\mathrm{B}_{\text {original }}$ ? $\mathrm{B}_{\text {extension }}$ ? \\
No quality information: & $\mathrm{B}_{1}+$ & \\
Attribute & $\mathrm{B}_{2}-$ & $\mathrm{B}_{\text {original }}$ ? $\mathrm{B}_{\text {extension }}$ ? \\
No attribute & $\mathrm{B}_{1} \mathrm{~A}_{1}$ & $\mathrm{~B}_{\text {original }}$ ? $\mathrm{B}_{\text {extension }}$ ? \\
\hline
\end{tabular}

NOTE. $-\mathrm{B}=$ brand; $\mathrm{A}=$ attribute; $+=$ high quality; $-=$ low quality; original = original category; extension = extension category; and ? = a test item in which no quality information is given and participants are asked to predict quality.

[Received June 2001. Revised July 2002. David Glen Mick served as editor and Frank R. Kardes served as associate editor for this article.]

\section{REFERENCES}

Aaker, David A. (1991), Managing Brand Equity: Capitalizing on the Value of a Brand Name, New York: Free Press.

Anderson, John R. and Gordon H. Bower (1973), Human Associative Memory, New York: Halstead.

Anderson, John R. and Christian Lebiere (1998), The Atomic Components of Thought, Mahwah, NJ: Erlbaum.

Baker, A. G., Frédéric Vallée-Tourangeau, and Robin A. Murphy (2000), "Asymptotic Judgment of Cause in a Relative Validity Paradigm," Memory and Cognition, 28 (April), 466-479.

Broniarczyk, Susan M. and Joseph W. Alba (1994), "The Importance of the Brand in Brand Extension," Journal of Marketing Research, 31 (May), 214-228.

Brown, Christina L. and Gregory S. Carpenter (2000), "Why Is the Trivial Important? A Reasons-Based Account for the Effects of Trivial Attributes on Choice," Journal of Consumer Research, 26 (March), 372-385.

Carpenter, Gregory S., Rashi Glazer, and Kent Nakamoto (1994), "Meaningful Brands from Meaningless Differentiation: The Dependence on Irrelevant Attributes," Journal of Marketing Research, 31 (August), 339-350.

Cheng, Patricia W. (1997), "From Covariation to Causation: A Causal Power Theory," Psychological Review, 104 (April), $367-405$.

Desai, Kalpesh Kaushik and Kevin Lane Keller (2002), "The Effects of Ingredient Branding Strategies on Host Brand Extendibility," Journal of Marketing, 66 (January), 73-93.

Erdem, Tülin and Joffre Swait (1998), "Brand Equity as a Signaling Phenomenon," Journal of Consumer Psychology, 7 (2), $131-157$.

Fournier, Susan (1998), "Consumers and Their Brands: Developing Relationship Theory in Consumer Research," Journal of Consumer Research, 24 (March), 343-373.

Gluck, Mark A. and Gordon H. Bower (1988), "From Conditioning to Category Learning: An Adaptive Network Model," Journal of Experimental Psychology: General, 117 (September), 227-247.

Green, Paul E. and Yoram Wind (1975), "New Ways to Measure Consumers' Judgments," Harvard Business Review, 53 (July-August), 107-117.

Hoch, Stephen J. and John Deighton (1989), "Managing What Consumers Learn from Experience," Journal of Marketing, 53 (April), 1-20.

Hoch, Stephen J. and Young-Won Ha (1986), "Consumer Learning: Advertising and the Ambiguity of Product Experience," Journal of Consumer Research, 13 (September), 221-233.

Hutchinson, J. Wesley and Joseph W. Alba (1991), "Ignoring Irrelevant Information: Situational Determinants of Consumer Learning," Journal of Consumer Research, 18 (December), 325-345.

Keller, Kevin Lane (1993), "Conceptualizing, Measuring, and Managing Customer-Based Brand Equity," Journal of Marketing, 57 (January), 1-22.

(1998), Strategic Brand Management: Building, Measuring, and Managing Brand Equity, Upper Saddle River, NJ: Prentice-Hall. 
Kelley, Harold H. (1973), "The Process of Causal Attribution," American Psychologist, 28 (February), 107-128.

Lober, Klaus and David R. Shanks (2000), "Is Causal Induction Based on Causal Power? Critique of Cheng (1997)," Psychological Review, 107 (January), 195-212.

Louviere, Jordan and Richard Johnson (1988), "Measuring Brand Image with Conjoint Analysis and Choice Models," in Defining, Measuring, and Managing Brand Equity: A Conference Summary, ed. Lance Leuthesser, Report 88-104, Cambridge, MA: Marketing Science Institute, 20-22.

Muthukrishnan, A. V. and Frank R. Kardes (2001), "Persistent Preferences for Product Attributes: The Effects of the Initial Choice Context and Uninformative Experience," Journal of Consumer Research, 28 (June), 89-104.

Park, Chan Su and V. Srinivasan (1994), "A Survey-Based Method for Measuring and Understanding Brand Equity and Its Extendibility," Journal of Marketing Research, 31 (May), 271-288.

Pearce, John M. and Mark E. Bouton (2001), "Theories of Associative Learning in Animals," Annual Review of Psychology, 52, 111-139.
Shanks, David R., Douglas L. Medin, and Keith J. Holyoak, eds. (1996), The Psychology of Learning and Motivation, Vol. 34, Causal Learning, San Diego, CA: Academic Press.

Simonson, Itamar, Ziv Carmon, and Suzanne O'Curry (1994), "Experimental Evidence on the Negative Effect of Product Features and Sales Promotions on Brand Choice," Marketing Science, 13 (Winter), 23-40.

Simonson, Itamar, Stephen M. Nowlis, and Yael Simonson (1993), "The Effect of Irrelevant Preference Arguments on Consumer Choice," Journal of Consumer Psychology, 2 (3), 287-306.

Van Osselaer, Stijn M. J. and Joseph W. Alba (2000), "Consumer Learning and Brand Equity," Journal of Consumer Research, 27 (June), 1-16.

Van Osselaer, Stijn M. J. and Chris Janiszewski (2001), "Two Ways of Learning Brand Associations," Journal of Consumer Research, 28 (September), 202-223.

Wood, Stacy L. (2001), "Remote Purchasing Environments: The Influence of Return Policy Leniency on Two-Stage Decision Processes," Journal of Marketing Research, 38 (May), 157-169. 
Copyright of Journal of Consumer Research is the property of Journal of Consumer Research, Inc. and its content may not be copied or emailed to multiple sites or posted to a listserv without the copyright holder's express written permission. However, users may print, download, or email articles for individual use. 